\title{
Simental Irkı Bir Buzağıdaki Üretral Dilatasyon Olgusunun Klinik, Radyolojik, Ultrasonografik Tanısı ve Tedavisi
}

\author{
Cihan GÜNAY ${ }^{1, a}$, Eren POLAT ${ }^{1, b,{ }^{*}}$, Aydın SAĞLIYAN ${ }^{1, c}$ \\ ${ }^{1}$ Fırat Üniversitesi, Veteriner Fakültesi, Cerrahi Anabilim Dalı, Elazıı̆, Türkiye. \\ aORCID: 0000-0002-0476-6164, bORCID: 0000-0002-3999-1310, 'ORCID: 0000-0002-8226-0740
}

\begin{abstract}
Geliș Tarihi: 13.02.2020
Kabul Tarihi: 06.05.2020

Özet: Bu olgu sunumunda, 4 günlük simental ırkı erkek bir buzağıda karşılaşılan üretral dilatasyon olgusunun klinik, radyografik, ultrasonografik tanısı ve tedavisi tanımlandı. Klinik muayenesinde disüri ve perineal bölgede içeriği idrar olan bir şişkinlik tespit edilen buzağının yapılan radyografik ve ultrasonografik muayenesi sonucu üretral dilatasyonu olduğu tespit edildi. Genel anestezi altında, şişkinlik bulunan bölge üzerinde $6 \mathrm{~cm}$ uzunluğunda bir ensizyon yapıldıktan sonra, deri katmanı geçilerek dilatasyonun olduğu bölgeye ulaşıldı. İdrarın boşaltılmasının ardından, üretranın dilate olan alanı daraltılarak üretrostomi işlemi yapıldı. Operasyon sonrası hayvana postoperatif olarak 7 gün parenteral antibiyotik uygulandı. Operasyonu takiben ilk hafta sadece üretrostomi yapılan bölgeden idrarını yapan buzağının sonraki süreçte idrarını penisten de yapmaya başladığı gözlendi. Bu sebeple üretrostomi ile oluşturulan açıklık kapatılarak hayvan kontrol altına alındı. Bir ay sonra hasta sahibi ile yapılan görüşmede hayvanın sağlık durumunun iyi olduğu öğrenildi.
\end{abstract}

Anahtar Kelimeler: Buzağı, Konjenital, Üretral dilatasyon, Uretrostomi

\section{Clinical, Radiological, Ultrasonographic Diagnosis and Treatment of Urethral Dilatation Case in a Simental Calf}

Abstract: In this case report, the clinical, radiographic, ultrasonographic diagnosis, and treatment of the urethral dilatation case encountered in a 4-day, simental, male calf were discussed. In the clinical examination of the calf, after the presence of dysuria and a swelling that contained urine in the perineal region, urethral dilatation was detected as a result of the radiographic and ultrasonographic examination. Under general anesthesia, after a $6 \mathrm{~cm}$ incision was made on the area with swelling, the area where the dilatation was reached was passed bypassing the skin layer. After draining the urine, urethrostomy was performed by narrowing the dilated area of the urethra. After the operation, the animal was administered parenteral antibiotics 7 days postoperatively. Following the operation, it was observed that the calf, which urinated only from the urethrostomal region in the first week, made urine from the penis in the next process. For this reason, the hole created by urethrostomy was closed and the animal was taken under control. One month later, during the meeting with the owner, it was learned that the animal was in good health.

Keywords: Calf, Congenital, Urethral dilatation, Urethrostomy.

\section{Giriş}

Ürogenital sistem anomalileri sindirim sistemi anomalileri ile birlikte gerek buzağılarda gerek ise diğer evcil hayvanlarda en çok karşılaşılan konjenital anomaliler arasında yer almaktadır (Chauhan ve ark., 2011; Durmuş ve Polat, 2019; Özaydın ve ark., 2016; Varol ve ark., 2018; Yayla ve ark., 2016). Üretral dilatasyonun patogenezisinde, diğer konjenital anomalilerde olduğu gibi genetik faktörler, intrauterin dönemdeki enfeksiyöz hastalıklar, gebelik sırasında oluşan intoksikasyonlar ve gebeliğin erken döneminde yapılan rektal muayeneler yatmaktadır (Bademkıran ve ark., 2009; Baran ve ark., 2015; Chauhan ve ark., 2011; Durmuş ve Polat, 2019; Özaydın ve ark., 2016; Öztürk ve ark., 2002; Varol ve ark., 2018; Yayla ve ark., 2016). Bazı araştırmacılar ise geçici üretral obstrüksiyonlarında üretral dilatasyona sebep olabileceğini bildirmişlerdir (Marzok ve El-khodery, 2013; Öztürk ve ark., 2002).

Üretral dilatasyon olgularında hastanın perineal bölgesinde fluktuan, ağrısız bir şişlik ile beraber disüri ya da anüri gibi klinik bulgulara rastlanmaktadır (Anderson, 1993; Baran ve ark., 2015; Marzok ve El-khodery, 2013; Öztürk ve ark., 2002; Yayla ve ark., 2016). Direkt ve indirekt radyografik yöntemler ile ultrasonografi kullanılarak klinik bulgular desteklenip hastalığın tanısı yapılabilmektedir (Anderson, 1993; Baran ve ark., 2015; Marzok ve El-khodery, 2013; Öztürk ve ark., 2002; Vogel ve ark., 2011; Yayla ve ark. 2016). Bölgenin ultrasonografik incelemesinde, geniş lümene sahip, postskrotal bölgeye doğru uzanan, hipoekoik bir şişliğin olduğu görülür (Yayla ve ark. 2016). Üretral dilatasyonun tedavisi çoğunlukla üretrostomi veya dilate olan bölgenin eksizyonu ile 
yapılmaktadır (Anderson, 1993; Hussein, 2011; Marzok ve El-khodery, 2013; Öztürk ve ark., 2002; Vogel ve ark., 2011; Yayla ve ark., 2016).

$\mathrm{Bu}$ olgu sunumunda 4 günlük, simental ırkı, erkek bir buzağıda karşılaşılan üretral dilatasyon olgusunun klinik, radyografik, ultrasonografik tanısı ve tedavisi rapor edildi.

\section{Olgu Tanımı}

$\mathrm{Bu}$ olgu sunumunun konusunu, Firat Üniversitesi Hayvan Hastanesi Cerrahi Anabilim Dalı'na idrar yapmada güçlük ve perineal bölgede şişkinlik şikâyetiyle getirilen 4 günlük, simental ırkı, erkek bir buzağı oluşturdu.

Hayvana yapılan klinik muayenede, buzağının perineal bölgesinde fluktuan bir şişkinlik olduğu (Resim 1) ve disüri durumunun bulunduğu tespit

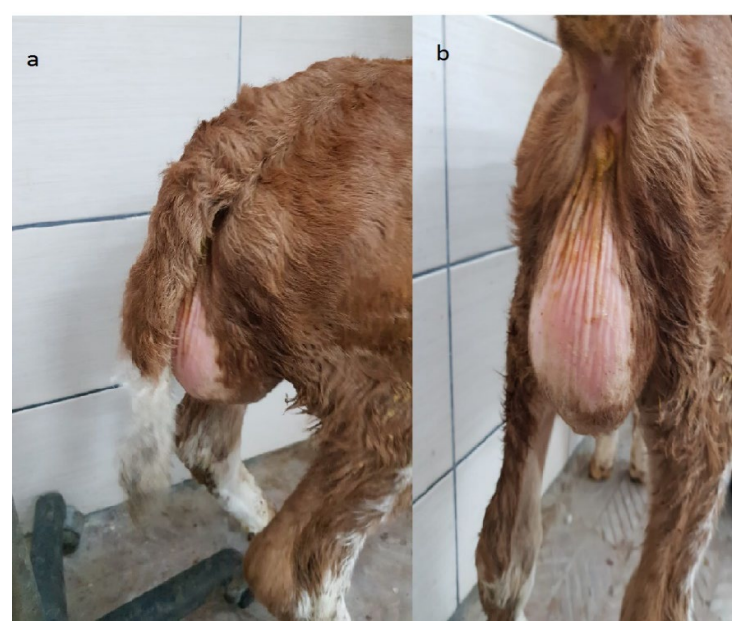

Resim 1. Buzağının perineal bölgesinde fluktuan bir şişkinlik $(a, b)$.

edildi. Fluktuan şişkinliğe palpasyon yapıldığında idrar akışının arttığı gözlendi. Yapılan punksiyon işlemi sonucunda şişkinlik içerisinden bulanık karakterde idrar geldiği tespit edildi.

Yapılan direkt radyografik muayenede postskrotal bölgede lümenli bir şişkinlik olduğu tespit edildi (Resim 2).

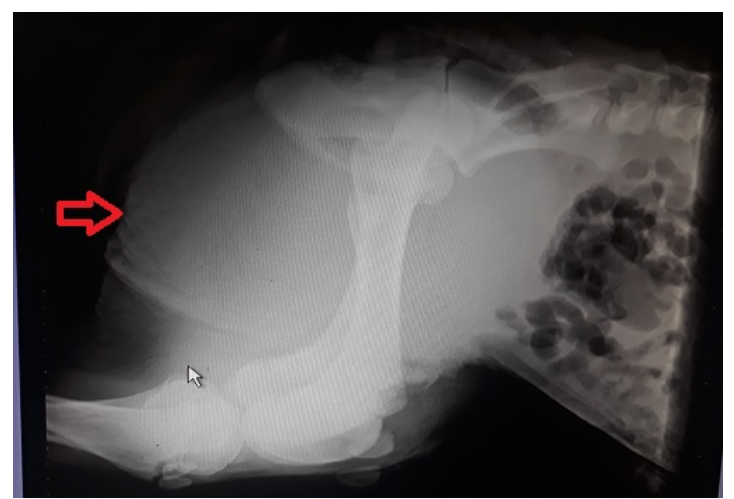

Resim 2. Direkt radyografik muayenede postskrotal bölgedeki şişkinliğin görüntüsü (kırmızı ok).
Indirekt radyografi uygulaması amacıyla $10 \mathrm{ml}$ iopromid içeren pozitif kontrast madde (Ultravist, Bayern, $623 \mathrm{mg} / \mathrm{ml}$ ) intravenöz yolla buzağıya verildi. Kontrast maddenin verilmesinden sonra 15 . ve 30. dakikalarda alınan radyografilerde üriner sistem organlarına kontrast maddenin geçmediği tespit edildi. Yapılan ultrasonografik muayenede ise, buzağının postskrotal bölgesinde, geniş lümene sahip, kalın duvarlı, içi hipoekoik bir sıvı ile dolu olan, çevre dokulardan rahatlıkla ayırt edilebilen ve idrar kesesini andıran bir şişkinlik olduğu tespit edildi (Resim 3). Yapılan muayeneler sonucunda buzağıya üretral dilatasyon tanısı konuldu.

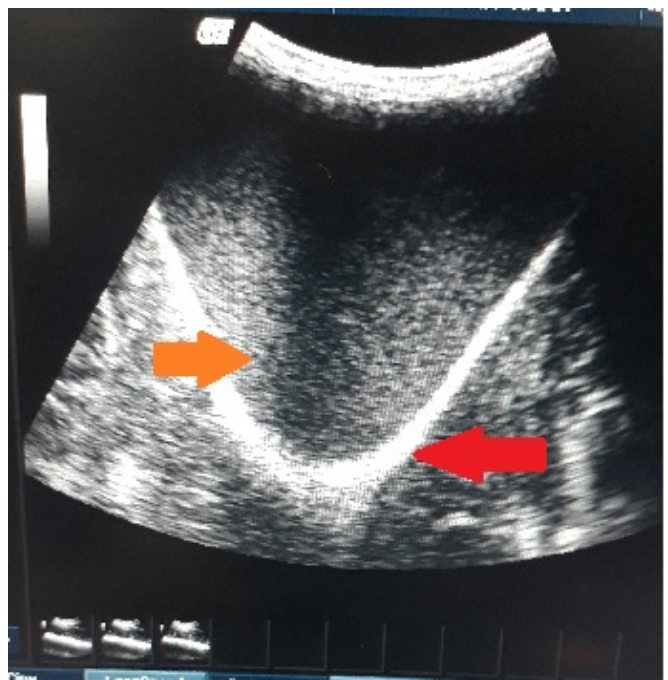

Resim 3. Postskrotal bölgedeki şişkinliğin ultrasonografi görüntüsü. Dilate üretranın kalınlaşan duvarı (kırmızı ok), Dilate üretral bölgede biriken idrar görüntüsü (turuncu ok)

Üretral dilatasyon tanısı konulan buzağıya operatif olarak müdahale edilmesine karar verildi. Operasyon için hayvana sedasyon amacıyla 0.2 $\mathrm{mg} / \mathrm{kg}$ dozunda ksilazin hidroklorür (Rompun, Bayer, $23.32 \mathrm{mg} / \mathrm{ml}$ ) intramuskuler yolla verildi. Buzağıya ksilazin hidroklorür uygulamasından 10 dakika sonra $4 \mathrm{mg} / \mathrm{kg}$ dozunda ketamin hidroklorür (Ketasol \%10, İnterhas, $100 \mathrm{mg} / \mathrm{ml}$ ) verilerek genel anesteziye alındı. Sternal pozisyonda operasyon masasına alınan hayvanın perineal bölgesinin traş ve dezenfeksiyonunu takiben operasyon bölgesi serviyet örtüleriyle sınırlandırıldı. Perineal bölgedeki şişkinliğin etrafına lidokain hidroklorür (Vilcain, Vilsan, $20 \mathrm{mg} / \mathrm{ml}$ ) kullanılarak lokal infiltrasyon anestezisi yapıldı.

Perineal bölgedeki şişkinlik üzerinde $6 \mathrm{~cm}$ uzunluğunda bir ensizyon yapılarak deri katmanı geçildi ve küt diseksiyon ile üretranın dilate olduğu bölgeye ulaşıldı. Üretranın dilate olan kısmı ensize edilip idrar boşaltıldıktan sonra, üretranın dilate olan kısmı eksize edilerek daraltıldı. Hayvan tamamen iyileşene kadar idrar yapmada güçlük yaşamaması için üretra sirküler olarak emilebilir 
sütur materyaliyle (Vicryl, USP 2/0) deriye tespit edilerek üretrostomi işlemi gerçekleştirildi. Hayvanın genel durumunun acil olmasından ve uygun büyüklükte sonda bulunmamasından dolayı gerek operasyon sırasında gerek postoperatif olarak sonda uygulaması yapılamadı. Fakat ne operasyon sırasında ne sonrasında bu durumdan kaynaklı komplikasyona rastlanmadı.

Operasyon sonrası hayvana 7 gün boyunca $8.75 \mathrm{mg} / \mathrm{kg}$ dozunda amoksisilin-klavunik asit (Synulox, Pfizer, $175 \mathrm{mg} / \mathrm{ml}$ ) uygulandı. Operasyonu takiben ilk hafta sadece üretrostomi yapılan bölgeden idrarını yapan buzağının sonraki süreçte idrarını penisten de yaptığı gözlendi. Bu sebeple üretrostomi ile oluşturulan açıklık kapatılarak hayvan kontrol altına alındı. Bir ay sonra hasta sahibi ile yapılan görüşmede hayvanın sağlık durumunun iyi olduğu öğrenildi.

\section{Tartışma ve Sonuç}

Ürogenital sistem anomalileri, gerek buzağılarda gerekse diğer evcil hayvanlarda sindirim sistemi anomalileri ile birlikte en çok karşılaşılan konjenital anomalilerdir (Chauhan ve ark., 2011; Durmuş ve Polat, 2019; Özaydın ve ark., 2016; Varol ve ark., 2018; Yayla ve ark., 2016). Kaya ve ark. (2011), buzağılarda karşılaşılan konjenital anomalilerin \%7.22'sini üriner sistem anomalilerinin oluşturduğunu bildirmişlerdir. Yine Aksoy ve ark. (2006) ise, ruminantlarda konjenital anomalilerin \%7.3'ünü üriner sistem anomalilerinin oluşturduğunu bildirmişlerdir. Bu olgu sunumunda da 4 günlük, erkek, simental ırkı bir buzağıda karşılaşılan üretral dilatasyon olgusu konu edildi.

Ürogenital sistemin konjenital anomalileri çoğunlukla multiple olgular şeklinde karşımıza çıkmaktadır. Üretral dilatasyon olgularının da çoğunlukla bu durumla uyumluluk gösterdiği bilinmektedir. Baran ve ark. (2015), biri bir günlük diğeri on günlük iki oğlakta penis aplazisi ve fimozis ile birlikte şekillenen üretral dilatasyon olgusunu bildirmişlerdir. Öztürk ve ark. (2002), üç günlük, Montofon ırkı, erkek bir buzağıda penis aplazisi ve anorşidizm ile birlikte gelişen üretral dilatasyon olgusunu bildirmişlerdir. Yine Yayla ve ark. (2016) ise, bir aylık, Simental ırkı, erkek bir buzağıda rektoüretral fistül ve segmental üretral agenezi ile birlikte şekillenen üretral dilatasyon olgusunu bildirmişlerdir. Üretral dilatasyon nadiren tek bir olgu olarak görülebilmektedir. Anderson ve ark. (1993), dört aylık Charolais-cross ırkı, erkek bir buzağıda üretral dilatasyon olgusunun tek başına seyrettiğini bildirmişlerdir. Bu olgu sunumunda da üretral dilatasyon olgusu sıklıkla görüldüğü durumun aksine tek başına görülmesinden kaynaklı olması yönüyle önem arz etmektedir.
Üretral dilatasyon olgularında, hastanın perineal bölgesinde fluktuan, ağrısız bir şişlik ile beraber disüri ya da anüri gibi klinik bulgulara rastlanmaktadır (Anderson, 1993; Baran ve ark., 2015; Marzok ve El-khodery, 2013; Öztürk ve ark., 2002; Yayla ve ark., 2016). Sunulan bu olguda da klinik bulguların diğer üretral dilatasyon olgularında gözlenen klinik bulgular ile uyumluluk gösterdiği görüldü. Radyografik muayenede dilatasyonun şekillendiği bölgeye göre farklı araştırmacılar farklı bulgular tespit ettiklerini bildirmişlerdir. Öztürk ve ark. (2002), perineal bölgedeki şişkinlik içerisine 20 $\mathrm{ml}$ meglumine-sodyum diatrizoate maddesini vererek aldıkları kontrast radyografide, üretranın ischial bölgede sonlandığını ve kısa üretra bölümünde dilatasyon şekillendiğini bildirmişlerdir. Baran ve ark. (2015), üretral dilatasyonu olan iki oğlakta intravenöz pyelografi ile tanıya gitmek istemişler fakat herhangi bir anormalliteye rastlamadıklarını bildirmişlerdir. $\mathrm{Bu}$ olgu sunumunda da üretral dilatasyon şüphesi olan buzağıya hem direkt hem indirekt radyografi uygulaması yapıldı. Direkt radyografide postskrotal bölgede yumuşak doku benzeri kontrast veren bir şişkinlik olduğu; indirekt radyografide ise direkt radyografi bulgularını öteye götürecek bir anormalitenin bulunmadığı tespit edildi.

Üretral dilatasyonun tanısında ultrasonografik muayene önemli ipuçları vermektedir. Perineal bölgedeki şişkinliğin ultrasonografik incelemesinde postskrotal bölgeye yerleşmiş, geniş lümenli, kalın duvarlı, içerisinde hipoekoik görünümde sıvı olan bir yapının varlığı üretral dilatasyon tespitini güçlendirmektedir (Vogel ve ark., 2011; Yayla ve ark., 2016). Karşılaşılan bu olguda da perineal bölge üzerindeki şişkinliğin ultrasonografisinde; kalın duvarlı, hipoekoik görünümde içerik bulunan geniş lümenli idrar kesesini andıran bir yapı tespit edildi.

Üretral dilatasyon, çoğunlukla üretrostomi veya dilate olan bölgenin eksizyonu yapılarak tedavi edilmektedir (Anderson, 1993; Hussein, 2011; Marzok ve El-khodery, 2013; Öztürk ve ark., 2002; Vogel ve ark., 2011; Yayla ve ark., 2016). Öztürk ve ark. (2002), üretral dilatasyonlu Montofon ırkı bir buzağıya üretrostomi operasyonu yaptıklarını ve hayvanın bir ay sonra yapılan kontrollerinde sağlıklı şekilde yaşamını sürdürdüğünü bildirmişlerdir. Baran ve ark. (2015), üretral dilatasyonu ve fimozisi olan iki oğlağın penil üretrasını ampute ederek üretrostomi yaptıklarını ve herhangi bir komplikasyon ile karşılaşmadıklarını bildirmişlerdir. $\mathrm{Bu}$ olgu sunumunda da üretranın dilate olan kısmı eksize edilip daraltıldıktan sonra üretrostomi işlemi yapılarak üretra deriye tespit edildi. Postoperatif birinci hafta sonunda hayvanın hem üretrostomi ile oluşturulan açıklıktan hem de penisten idrar yapması nedeniyle üretrostomi ile oluşturulan 
açıklık dikilerek kapatıldı. Yapılan bir aylık kontroller sonrası herhangi bir komplikasyon şekillenmediği ve hayvanın hayatına normal şekilde devam ettiği saptandı.

Sonuç olarak, klinik muayene ile tespiti kolay görünen fakat üriner sistemdeki divertikül, üretra rupturu ve üriner sistemin diğer anomalileri ile karışma ihtimali yüksek olan üretral dilatasyon olgusunun klinik, radyografik, ultrasonografik bulgular ve tedavisi paylaşılarak saha şartlarında çalışan meslektaşlarımıza ışık tutulacağı ve literatüre katkı sağlanacağı düşünülmüştür.

\section{Kaynaklar}

Aksoy Ö, Kılıç E, Öztürk S, Özaydın I, Kurt B, Baran V, 2006: Buzağı, kuzu ve oğlaklarda karşılaşılan doğmasal anomaliler: 1996-2005 (262) olgu. Kafkas Üniv Vet Fak Derg, 12(2), 147-154.

Anderson DE, 1993: Urethral recess dilatation in Charolais-cross bull calf. Can Vet J, 34, 234-235.

Baran V, Kılıç E, Yayla S, Karakurt E, 2015: iki oğlakta karşılaşılan üretral dilatasyon ve fimozis olgusu. Harran Üniv Vet Fak Derg, 4(1), 30-32.

Bademkıran S, İçen H, Kurt D, 2009: Congenital rectovaginal fistula with atresia ani in a heifer. YYÜ Vet Fak Derg, 20(1), 61-64.

Chauhan PM, Parmar VR, Patel TP, Thakor KB, Parikh SS, 2011: Atresia ani: a congenital defect and its successful management in non-descript calf. IJAVMS, 5(6), 520-522.

Durmuş AS, Polat E, 2019: Simental ırkı bir buzağıda atresi ani ve rektoüretral fistül olgusu. Harran Üniv Vet Fak Derg, 8(2), 246-248.
Kaya M, Okumus Z, Doğan E, Çetin EM, Yanmaz LE, 2011: Erzurum Yöresindeki Buzağılarda Doğmasal Anomalilerin Görülme Sıklığı ve Sağkalım Oranları. FÜ Sağ Bil Vet Derg, 25 (2), 83 - 93.

Hussein KE, 2011: Surgical management of some congenital anomalies in ruminants. Eurasian $\mathrm{J}$ Vet Sci, 27(4), 245-249.

Marzok MA, El-khodery S, 2013: A comparison of surgical out comes of perineal urethrostomy plus penile resection and perineal urethrostomy in twelve calves with perineal or prescrotal urethral dilatation. Open Veterinary Journal, 3(2), 106-113.

Özaydın I, Kılıç E, Aksoy Ö, Cihan M, Güngör E, 2006: Bir buzağıda üçlü malformasyon: atrezi ani, rektouretral fistül ve pygomelia. Kafkas Üniv Vet Fak Derg, 12(2), 189-191.

Öztürk S, Kılıç E, Arancı A, Uyguntürk A, 2002: Montofon bir buzağıda aplazya penis, anorşidizm ve üretral dilatasyon olgusu. Kafkas Üniv Vet Fak Derg, 8(1), 63-65.

Varol K, Atalan G, Günes V, Alpman U, Yönez MK, 2018: A case of atresia ani in an anatolian water buffalo calf. Erciyes Üniv Vet Fak Derg, 15(3), 271-275.

Vogel SR, Dore E, Breteau G, Desrochers A, Babkine M, Nichols S, 2011: Congenital enlargement of the suburethral diverticulum in a holstein calf. Can Vet J, 52, 173-176.

Yayla S, Kılıç E, Baran V, Özen H, 2016: A case of congenital rectourethral fistula, urethral dilatation and segmental urethral agenesis encountered in a calf. Harran Üniv Vet Fak Derg, 5(1), 70-73.

*Yazışma Adresi: Eren POLAT

Fırat Üniversitesi, Veteriner Fakültesi, Cerrahi Anabilim Dalı, Elazı̆̆, Türkiye.

E-mail: erenpolat@firat.edu.tr 